\title{
RESPONSE TO APEL AND DARMARK: EVOLUTION AND MATERIAL CULTURE
}

\section{Liv Nilsson Stutz}

Jan Apel and Kim Darmark boldly deliver an argument to address what they regard as shortcomings in contemporary Scandinavian archaeology - which they describe as narrative, fragmented and anti-scientific to the point of being effectively marginalized from other disciplines. To come to terms with this, they call for theoretical debate and propose the introduction of evolutionary issues in Swedish archaeology. The proposition is given an ambitious scope. An evolutionary perspective will, according to the authors, "have a fundamental effect on the questions asked, the taxonomies employed, and the role of archaeology as a discipline." We are, it would seem, facing a potential paradigm shift in Scandinavian archaeology. While I warmly welcome the call for theoretical debate, I am not convinced by the authors' argument that evolutionary archaeology is the answer to the wide set of questions that archaeology encompasses today. To borrow from the authors' own vocabulary, I am not convinced that Darwinian evolutionary perspectives will have the replicative success the authors hope for in archaeological theory and debate. This, I argue, is not because the ideas are altogether irrelevant or uninteresting, but because they simply are not fit to inhabit the many niches of contemporary archaeological thought and may even contribute to marginalizing the discipline even further.

I want to make it clear that my skepticism does not reside in a kneejerk reaction to natural scientific perspectives in the quest to understand humanity and human history. For example, I sympathize with 
Apel and Darmark when they claim that some contemporary archaeological perspectives appear to completely disregard the biological reality of the human body, and that these perspectives ironically tend to reproduce a mind-body dualism which their proponents work so hard at deconstructing. I also think that Apel and Darmark effectively communicate the difference between their own position and that of ecological determinism, teleological evolutionary thinking and the many other misconceptions that can result from a very superficial glance at Darwinism and its potential for characterizing biological and cultural change. In particular I appreciate the introduction of a materialistic perspective in material culture studies as a way to once and for all deconstruct typologies. By employing a terminology that openly acknowledges variability within the defined type (or species), and readily provides a means to understand change through selection, drift, founder effect etc, we can better reflect over taxonomy and typology while emphasizing the process of evolution as constant and variability as inherent in the system, and as driving change. The perspective further invites us to think about the human being behind the artifact as it provides a way for us to reflect over the many human, culturally embedded factors that can influence the production process-including mistakes, innovations, repetition, learning, authority, peer pressure, etc. While this may not be earth shattering for many archaeologists, who indeed may implicitly incorporate these lines of thought in their work, the systematic way in which these cladistics of material culture could be employed, if successfully introduced, could very well result in a minor paradigm shift for technological and typological studies. Most post-processual archaeologists would have to agree with the idea that the names we give to things structure the way in which we think about them and thus are important for knowledge production.

But the ambition of the authors does not end here and neither does the paradigm of evolutionary archaeology; and this is where things become problematic. While the use of evolutionary terminology as a literal "figure of speech" may be an advantage when limited to the understanding of typology and technology, it becomes problematic when extended to understanding cultural change as a whole. The exclusive focus on material culture seems to betray an archaeological myopia which confuses people with flint and pottery, and at least implicitly it appears to argue that the material culture is the driving force of change, rather than a reflection of it, or possibly a party in a dia- 
lectical relationship. The paradigm makes it operationally possible to start and end the analysis of past culture in the study of material culture without incorporating non-material processes into the equation. There is even an odd vagueness in the argumentation as to what it is that actually evolves and where to locate the driving forces. What is suggested appears to be a shift away from an anthropocentric archaeology in favor of a more systemic view of human culture as a series of interactions between material and people. The authors know just as well as I do that pots do not evolve on their own. Pots are made. This is one of their points and they have skillfully argued for a series of important cultural, social, cognitive and psychological factors that affect the processes of change in material culture. Why, then, are people not given a central place in the reasoning within the evolutionary perspective? To illustrate my point, I want to draw attention to the example of selection of material culture traits cited by the authors themselves. The authors observe a similarity in technological change in the flint arrowheads of the Scandinavian Pitted Ware culture and the Upper Volga Neolithic. They continue to compare the "evolutionary histories" (sic!) of Solutrean laurel leaf points from the Gravettian and Aterian periods, and the Big Arrowhead Industry in Anatolia and the Levant. The technological similarities which seem to indicate a gradual selection of traits are described in some detail, but the explanation offered is so general that it is reasonable to ask what this new paradigm can really offer in terms of explaining the past. The similar change in unrelated contexts, the authors argue, appears to suggest a common denominator, "the nature of which is uncertain." While I acknowledge that this insight probably is valuable for a specialist in lithic technology, I strongly object to the proposal that this approach is applicable for archaeology as a larger field. What leaves me puzzled is that the authors actually have presented the tools to discuss, at least, alternative hypotheses for the processes observed. Indeed they could talk about biased transmission or other factors within the social environment that they acknowledge as significant. Yet they abstain. It feels like a lost opportunity, but I suspect that it has something to do with the explicit preference for natural sciences within evolutionary archaeology, which may not be enough to fully and scientifically address the complexities of human culture. To understand the changes in the material culture of the past, it may be impossible to escape the context specific and the narrative. 
This observation leads to a second point. The article appears to simultaneously address and confuse two main issues. On the one hand, it aims at introducing the evolutionary perspective in a contemporary Scandinavian archaeology deemed too - for lack of a better term post-processual. On the other hand, the authors position their proposal as a radically different alternative. In the spirit of debate this may make sense at first glance, but I would argue that it leads the authors to a difficult impasse. In doing so, they mix up their cards and create a connection between science, natural science and evolutionary theory which is set up as an opposition to narrative historical and contextually embedded archaeology. For example, they argue that an evolutionary perspective easily can be combined with action theory. Why not go even further in the cross-disciplinary quest and pair up with practice theory? In their eagerness to distance themselves from what they view as an unproductive humanistic archaeology they undermine their own argument that, at least in theory, they take social and cultural factors into consideration. Through their explicit distancing they continue to reproduce a separation between the humanities and social sciences, on the one hand, and the natural sciences, on the other. I still am not convinced that this is beneficial for archaeology.

The critique in this article is clearly directed at Scandinavian archaeologists in general and perhaps Swedish archaeologists in particular. Contemporary Swedish archaeology constitutes a context in which the authors find themselves facing a theoretical challenge. The authors do a great job at positioning themselves and preempting some of the skepticism they foresee in the form of prejudiced reactions to the natural sciences. However, I would argue that in the process of situating themselves in the debate they also overstate the differences between the natural and social sciences and their potential role for archaeology. Moreover, they seem to indicate that while the paradigm they propose may not yet have gained ground in mainstream Swedish archaeology, it has elsewhere. I think it is important to point out that while evolutionary perspectives may be more common in the archaeological communities in the UK and the US, evolutionary archaeology per se remains limited and can hardly be described as mainstream, at least here in the US, where the same need to protest against a contemporary post-processual canon within the discipline simply is not a central concern, and where evolutionary archaeology exists as a minor contingent within a much broader processual archaeology. 
Finally, I want to address the authors' claim that evolutionary archaeology would bring Scandinavian archaeology out of its perceived marginalization and would make it more relevant for cross-disciplinary studies and possibly for the general public. Apel and Darmark are probably right in the sense that a popularized version of an evolutionary archaeology reading of the past could probably catch the general interest as well as any book by Jared Diamond or Richard Dawkins. But I suspect that that version is not going to include the nuanced perspectives that they hint at in their general presentation. As far as cross-disciplinary collaborations go, I am not convinced that archaeology needs to dress up as a natural science to be relevant. I honestly believe that position will be severely challenged the moment we try to actually interpret our observations (as my critique of the case study indicates). The reason for this is not that we are less scientific than others, but simply that we are implicitly and explicitly cross-disciplinary and we should learn to embrace that fact instead of holding it against ourselves.

Liv Nilsson Stutz

Dept of Archaeology and Ancient History, Lund University, Sandgatan I, 22350 Lund, Sweden

Department of Anthropology, Emory University, 207 Anthropology Building, I 557 Dickey Dr., Atlanta, GA 30322, USA 
